\title{
Appendicitis in Pregnancy: Presentation, Management and Complications
}

\author{
Abdoulhossein Davoodabadi, ${ }^{1,}$ Hassan Davoodabadi, ${ }^{1}$ Hossein Akbari, ${ }^{2}$ and Monireh Janzamini ${ }^{1}$ \\ ${ }^{1}$ Departments of General Surgery Trauma Research Center, Kashan University of Medical Sciences, Kashan, IR Iran \\ ${ }^{2}$ Department of Biostatistics and Epidemiology, Social Determinants of Health Research Center, Kashan University of Medical Sciences, Kashan, IR Iran \\ "Corresponding author: Abdoulhossein Davoodabadi, Departments of General Surgery Trauma Research Center, Physical Education Office, Ministry of Sciences, Kashan \\ University of Medical Sciences, Kashan, IR Iran. E-mail: davoodabadi28ab@yahoo.com
}

Received 2014 April 23; Accepted 2014 October 12.

\begin{abstract}
Background: Diagnosis of acute appendicitis in pregnancy is difficult. Delay operation, increase complications.

Objectives: This study focused on early operation on base of careful history, precise physical examination, and rational close observation and evaluates its results with conventional investigation in pregnant women suspected acute appendicitis.

Materials and Methods: A cross sectional study in100 pregnant women and 100 aged matched non pregnant women underwent appendectomy during Sep 2011 - Dec 2014. The data were analyzed by chi-square test through SPSS 16.0.

Results: Age 16 - 37 years, mean age in pregnant women and no pregnant women were24.75 \pm 4.4 and $27.56 \pm 6.53$ years $(\mathrm{P}>0.05)$, respectively. 20 - 25 years age group, were more frequent $=44 \% .70 \%$ patients were gravid 1 , mean hospital stay in pregnant women, and non-pregnant women were $48 \pm 6$ and $85.2 \pm 43.19$ hours (P value $<0.001$. respectively. acute appendicitis was confirmed histological in non-pregnant was $72 \%$, but In pregnant women $62 \%$, most cases were in the third Trimester $66 \%(n=41)$. Peri umbilical pain, with migration to the right lower quadrant, was in $75 \%$ of patients. Right-lower-quadrant pain was the most common presenting symptom. Diagnosis (62\%) was made on base care full history and precise physical examination and close observation of $12 \pm 8$ hours. there were no maternal and fetal complications related to all of the appendectomies during the all trimester up to delivery period.

Conclusions: There are no diagnostic laboratory findings in acute appendicitis during pregnancy. Careful history and physical examination and close observation of $12 \pm 8$ hours are sufficient for surgery decision making. In spite of high negative appendectomy since it has no Surgical and obstetric complication, early Appendectomy without aggressive investigation recommend.
\end{abstract}

Keywords: Pregnancy, Appendectomy, Acute Appendicitis

\section{Background}

Acute appendicitis is the most common surgical Condition which requiring abdominal surgery during pregnancy, its incidence is reported to be between 1:1250 and 1:1500 pregnancies $[1,2]$. Acute appendicitis has a peak incidence in the second and third decades coinciding with the childbearing years [3]. Accurate diagnosis is difficult with the typical clinical picture being present in only $50 \%$ - $60 \%$ of cases $[4,5]$. With increasing gestational age reduces diagnostic accuracy and is associated with increased rates of appendiceal perforation and hence complications [6]. Furthermore, it have an unspecific clinical presentation, particularly close to term, due to a change in physiological and anatomical constitution. The complexity of the diagnosis is increased [7-9]. The high frequency of nausea, vomiting and abdominal pain elevated white cell count and left shift in neutrophils during pregnancy and general reluctance to operate unnecessarily, more investigation and prolong observation leads to the delayed appen- dectomy and increase complication $[10,11]$. The negative laparotomy rate for suspected appendicitis in obstetric cases is $25 \%$ - $50 \%$ compared with $15 \%$ - $35 \%$ in general surgical cases $[12,13]$. In the obstetric cases, the consequence of unnecessary surgery leads to increase rates of miscarriage, premature labor 15\% - 45\% and fetal loss [13]. However, delay to surgery is equally risky with rates of fetal loss reported to be $1.5 \%$ - $4 \%$ in 'uncomplicated appendicitis' and $21 \%$ - 35\% in the presence of 'ruptured appendicitis' [14, 15]. There are no scoring systems available specifically for the obstetric population, and those for the general population have variable reproducibility and less sensitivity in women [16]. The current analysis study has shown no capability of clinical parameters investigated to be useful in predicting appendicitis in pregnancy. Consequently, accurate diagnosis relies on astute clinical acumen, a high index of suspicion and an up to date awareness of available diagnostic tools. Compression ultrasounds in first and second trimester pregnancies have good diagnostic sensitiv- 
ity [17]. CT has been used to diagnosis however, has potential risk of the ionizing radiation to the fetus [18]. MRI has also been reported high sensitivity, specificity [19]. But it is not available to all pregnant patients. Until now, an aggressive surgical strategy is mandated to minimize the risk of maternal morbidity and fetal loss associated with ruptured appendicitis, resulting from delayed diagnosis [20]. Therefore in any pregnant patient, with newly right sided abdominal pain, guarding, rebound tenderness should always be considered appendicitis since laboratory data usually are not conclusive $[8,20]$. Careful history and physical examination is key to making the acceptable diagnosis [21].

\section{Objectives}

In this study, we present suspicious patients to acute appendicitis during pregnancy in order to evaluate the clinical presentation, management and complication and compare results of early operation strategy on base of Careful history, physical examination and rational close observation without conventional investigation (use of barium enema, CT scan and MRI).

\section{Materials and Methods}

In a cross sectional study, during Sep 2011 until Dec 2014, 100 consecutive pregnant women which suspicious to acute appendicitis, underwent open appendectomy. Clinical data included history, physical examination, right lower quadrant (RLQ) rebound tenderness, migration of pain from epigastrium to (RLQ), fever age of the patients, week of pregnancy, ultrasonography of appendix, uterus adenex and renal, leukocyte count, urinalysis, postoperative complications, outcome and also mean hospital stay, mean operative time was noted and were compared with 100 non pregnant women at the same age. In this study RLQ rebound tenderness in pregnancy was more important, than non-pregnant women were considered.

The diagnosis of acute appendicitis was made on base of careful physical examination careful history, ultrasound findings, and $12 \pm 8$ hours closed observation from onset of complains of abdominal pain. We do not used laparoscopy, more aggressive investigation such as abdominal CT SCAN, barium enema, or more prolong observation for decreasing negative appendectomies, as we did in non-pregnant cases. General anesthesia and McBurney's incision were used in all cases. No hormonal, tocolytic agent was administered. We avoided more stress induce to mother about maternal and fetal complications in order to reduce patients anxiety.
Our policy was safety as possible and on time appendectomy. We are aware of any adenexal problem before operation by ultra sonograghy, so any uterus and adenexal manipulation during appendectomy strictly avoided. In presence of negative appendectomy no any routine abdominal exploration was done. Trimesters define as: first trimester, 1 to 14 weeks; second trimester, 15 to 28 weeks; and third trimester, 29 to 42 weeks.

The negative appendectomy rates, pathologic diagnosis (i.e., normal vs. supperative vs. gangrene) and Incidences of events (trimester, Surgical procedures and obstetric and surgical morbidity and mortality) in pregnant and non-pregnant groups were compared using the chisquare test. Age distribution between two groups was compared using the student's t test. Continuous values (age and length of hospital stay). Criteria of statistical significant was a $\mathrm{P}<005$.Statistical analyses were performed by SPSS 16.0.

- Inclusion criteria: pregnant women suspicious to appendicitis, in childbearing age;

- Exclusion criteria: pregnant women with established peritonitis, multiple traumas, cecal perforation.

Quality of informed consent process in pregnant patients undergoing appendectomy: we explained the complication of related appendectomy include: fetal mortality, preterm labor or preterm delivery and also explained benefit of early appendectomy with high negative rate and more safety vs. delayed appendectomy and less negative rate but more complication to husband and his parents, which recorded and signed it in medical issue, but we avoided more stress induce to mother about maternal and fetal complications in order to reduce patients anxiety.

\section{Results}

The mean age of the pregnant patients were $(24.75 \pm$ 4.4 years and in non-pregnant patient were $(27.56 \pm 6.53)$ years respectively $(\mathrm{P}>0.05)$. The Incidence of appendicitis during pregnancy was estimated 1/350. 20 - 25 years age group were more frequent $=44 \%$ also in non-pregnant were $25 \%$ Table 1 . Acute appendicitis was confirmed histological in $72 \%$ of non pregnant women, but in pregnant was (62\%), which mostly were suppurative, gangrene in 2 case no perforation occurred. Thirty eight percent were negative appendicitis. In this study $70 \%$ of affected patients were in gravid 1, 21\% gravid 2, 6\% gravid 3 and 3\% gravid 4 . The first, second and third trimester positive appendectomy was 13 (21\%), 8 (13\%) and 41 (66\%) but in negative appendectomy were $3(8 \%), 22(58 \%)$ and $13(34 \%)$ respectively $\mathrm{P}<0.001$.

Although abdominal ultrasonography was performed in all patients, but its findings, which was suggestive for 
Table 1. Age Distribution in Pregnant and Non-Pregnant Patients

\begin{tabular}{lcc}
\hline Age & Pregnant & Non Pregnant \\
\hline Less than 20 years & 16 & 14 \\
\hline $\mathbf{2 0}-\mathbf{2 5}$ & 44 & 25 \\
\hline $\mathbf{2 5}-\mathbf{3 0}$ & 27 & 22 \\
\hline $\mathbf{3 0}$ - 35 & 12 & 21 \\
\hline More than 35 years & 1 & 18 \\
\hline Total & 100 & 100 \\
\hline
\end{tabular}

acute appendicitis, only in $26 \%$ was correlated with appendicitis $(\mathrm{P}=0.324)$ indeed Ultrasonography finding was helpful for roll out obstetric and renal disease.

Leukocytosis more than 10000 was \%75 in positive appendicitis and in negative appendicitis was 70\%. PMN in positive appendicitis was $77 \%$ and in negative appendicitis was $71 \%$ but on non-pregnant was $67 \%$. There are $75 \%$ correlation with rebound tenderness and superative appendicitis $\mathrm{P}=0.003$. In presence of rebound tenderness superative appendicitis were more than fivefold $\mathrm{OR}=5.78, \mathrm{CI}=$ 1.78 - 18.7). Urine analysis, mostly was normal no any different in positive appendectomy or negative appendectomy. More than half of patient have normal temperature, the rest have temperature 38 or less Table 2 . In follow-up that were performed up to normal delivery period, there was no maternal, fetal mortality or early delivery after appendectomy, morbidity also was as well as non-pregnant cases and had no significant difference. In Table 3 the mean hospital stay, and mean operative time were compared with 100 non pregnant women at the same age, had no significant difference. Close observation from onset of abdominal pain was1 \pm 8 hours, in non-pregnant was $31.2 \pm 19$ hours. The age of the non-pregnant patients $27.56 \pm 6.53$ Table 3.

\section{Discussion}

Since Babler first stated nearly 100 years ago, 'the mortality of appendicitis complicating pregnancy is the mortality of delay'. The wisdom of this statement has been repeatedly demonstrated that perforated appendicitis during pregnancy is associated with high maternal and fetal mortality. The important factor of perforation is delayed operation [20]. Thus, every effort should be on improving accuracy of diagnosis and early surgical approach with possible appendicitis.

New abdominal pain, in right lower quadrant is the most consistent sign of Appendicitis, however changes of position of appendix with gestational age and other anatomic and physiologic changes in pregnancy may also cause abdominal pain and interfere with correct appendicitis diagnosis $[3,13]$.

Our study showed beginning of pain from epigastrium, periomblical and migration to R L Q was in76\% of positive case, but this important sign was also in $29 \%$ of negative appendectomies. In 76\% of positive cases has R L $Q$ rebound tenderness also it was in $65 \%$ of negative appendectomy.

Therefore R L Q rebound tenderness and its migration is highly suggestive for appendicitis in pregnancy however in negative appendectomy may also present. The accuracy of diagnostic tools for appendicitis during pregnancy is known to be low and although abdominal ultrasonography was performed in all patients, but it suggestive for acute appendicitis only in $26 \%$, indeed Ultrasonography finding are helpful for other cause of appendicitis or assess the presence of an ovarian cyst or torsion of an adnexal mass and renal pathology [17]. Abdominal CT SCAN, MRI laparoscopy are useful for better diagnoses but it has limited option in pregnancy. Abdominal CT SCAN has been omitted to avoid exposing the fetus to harmful radiation and teratogenic risk, especially in the first trimester [18]. The accuracy of MRI for diagnose acute appendicitis in pregnancy is as high as $70 \%$ to $94 \%$.and should be used when feasible [19-22]. The cost effectiveness of MRI in this patient group also is uncertain, and for these reasons MRI is unlikely to become a routine examination available to all pregnant patients [23]. We do not used MRI neither in pregnancy nor in non-pregnant patients. Several studies have revealed early diagnostic laparoscopy is beneficial when appendicitis is suspected $[24,25]$. Laparoscopy is considered minimally invasive and safer than observation and re-evaluation. It can reduce the negative appendectomy rate but might raise the perforation rate [26]. The most recent systemic review with laparoscopy, fetal loss was significantly higher ( $5 \%$ to $6 \%$ ) compared to fetal loss with open appendectomy (1\% to $3 \%$ ) [27].

Thus the major diagnosis means of acute appendicitis in pregnancy was care full history and precise physical examination and close observation, which leads Accuracy of $62 \%$. In our study, $76 \%$ of positive appendicitis had leukocytosis, more than 10,000 , but leukocytosis in $70 \%$ negative appendicitis also occurred, thus leukocytosis, could not as a diagnostic measure considered. Mild to moderate leukocytosis are features common to both acute appendicitis and normal pregnanc $[12,28]$. polymorfonuclear also was increased both in positive and negative appendectomy and had no role in increasing diagnosis. However when it compared with non-pregnant patients were more increased. In a study revealed that the neutrophil to lymphocyte ratio $>5$ ), fever $<38^{\circ} \mathrm{C}$ ), white blood cell count 
Table 2. Clinical Manifestation of Appendicitis in Pregnant Patients ${ }^{\mathrm{a}}$

\begin{tabular}{|c|c|c|c|c|c|}
\hline \multirow[t]{2}{*}{ Variables } & \multicolumn{2}{|c|}{ Appendectomy Results } & \multirow[t]{2}{*}{ P Value } & \multirow[t]{2}{*}{ Odds Ratio } & \multirow[t]{2}{*}{ Confidence Interval } \\
\hline & Positive Appendectomy & Negative Appendectomy & & & \\
\hline Anorexia & 88 & 86 & - & - & - \\
\hline Fever $\leq 38^{\circ} \mathrm{C}$ & 47 & 42 & - & - & - \\
\hline RLQ Rebound tenderness & & & 0.003 & 5.78 & $1.78-18.7$ \\
\hline No & $15(24.1)$ & $13(35.3)$ & & & \\
\hline Yes & $47(75.9)$ & $25(64.7)$ & & & \\
\hline Migration of pain & & & 0.145 & 2.2 & $0.7-6.97$ \\
\hline No & $15(24.1)$ & $27(71)$ & & & \\
\hline Yes & $47(75.9)$ & $21(29)$ & & & \\
\hline Leukocytosis & & & 0.441 & 1.31 & $39-4.43$ \\
\hline No & $15(24.1)$ & $11(29.4)$ & & & \\
\hline Yes & $47(75.9)$ & $27(70.6)$ & & & \\
\hline
\end{tabular}

${ }^{\mathrm{a}}$ Values are expressed as No. (\%) or \%.

Table 3. Data Comparison Pregnant Women With Non-Pregnant Women

\begin{tabular}{|c|c|c|c|}
\hline Variables & Pregnant Women & Non-Pregnant Women & P Value $<0.001$ \\
\hline Age, y & & & - \\
\hline Less than 24 & 60 & 39 & \\
\hline $25-29$ & 27 & 22 & \\
\hline More than 30 & 13 & 39 & \\
\hline Mean \pm SD & $24.75 \pm 4.4$ & $27.56 \pm 6.53$ & \\
\hline Close observation, $\mathbf{h}$ & $12 \pm 8$ & $31.19 \pm 19.56$ & $<0.001$ \\
\hline \multicolumn{4}{|l|}{ Type of appendicitis } \\
\hline Gangrene & $2(2)$ & $17(17)$ & $<0.001$ \\
\hline Suppurative & $60(60)$ & $47(47)$ & 0.15 \\
\hline Perforated & 0 & $8(8)$ & 0.007 \\
\hline Catarrhal & $38(38)$ & $28(28)$ & - \\
\hline Peritonitis & 0 & 0 & - \\
\hline \multicolumn{4}{|c|}{ Maternal and fetal complications } \\
\hline Morbidity & 0 & 0 & - \\
\hline Death & 0 & 0 & - \\
\hline Hospital stay, h & $48 \pm 6$ & $85.2 \pm 43.19$ & $<0.001$ \\
\hline Mean operative time, min & $60 \pm 10$ & $60 \pm 5$ & - \\
\hline
\end{tabular}

${ }^{\mathrm{a}}$ Values are expressed as No. (\%) or \%.

$<11.5 \times 10^{3} / \mathrm{mm}^{3}$ and serum level of C-reactive protein $(<$ $110 \mathrm{mg} / \mathrm{L}$ ) is significantly associated with Catarrhal appendicitis [29]. Urine analysis, temperature and anorexia as do as non-pregnant patients were inconclusive. We have no maternal mortality or fetal demise, morbidity, after appen- dectomy. However recent study by McGory et al. reported that $4 \%$ of pregnant women who underwent negative appendicitis experienced fetal loss. They concluded that negative appendicitis in pregnant women is associated with a significant risk of fetal loss [13]. 
Fetal mortality is given as 5\% after appendicitis, whereas this rate increases to approximately $20 \%$ in perforated appendicitis. Similarly, maternal mortality also increases in perforated cases [15]. In a study by Kaori Ito et al. negative Appendectomy rate was significantly higher in pregnant women compared with non-pregnant women (36\% vs. 14\%). The fetal demise rate was highest (14\%) in the perforated group [30] although Perioperative assessment to avoid unnecessary exploration must be done when appendicitis is suspected, it seems that the more time to be under observe the more accuracy achieved but leads delayed operation and increasing hospital charge. Closed observation is effective for better diagnosis but delaying surgical intervention more than 24 hours after symptom onset increases the risk of perforation, which occurs in 14 to $43 \%$ of such patients. Early surgical intervention, with less than a 24 hours delay, has shown minimizing both maternal and fetal morbidity and mortality [12].

Closed observation in our patients was $12 \pm 8$ hours, when it compared with non-pregnant at the same age, $31.2 \pm 19$ hours which leads to $72 \%$ positive appendectomy, however had some disadvantage: gangrene17\% vs $2 \%$, perforation $8 \%$ vs. $0 \%$, hospital stay $85.2 \pm 43.19$ hours vs 48 \pm 6 hours, need more antibiotics administration with fetal harm consideration and more Hospital charges, are notable. It must considered balance between high negative appendectomy rate without complication and more diagnosis, more complication and its cost benefits of each strategy. Our strategy is especially suitable in developing country with minimal equipment and high incidence rate of appendicitis during pregnancy (1/350 vs 1/1250 in western country). Indeed a sonography for assessment of appendix, roll out of obstetric and renal disease, careful physical examination and history, rational closed observation were sufficient diagnostic means and decision making.

It seems that the major cause of 100 uncomplicated appendicitis in pregnant women was on time operation, avoid prolonged observation, avoid unnecessary intestinal, lymph node, meckle diverticulume exploration, uterine and adexanal manipulation, in confront with catarrhal appendicitis.

The negative laparotomy rate for suspected appendicitis in obstetric cases were reported $25 \%$ - 50\%, in nonobstetric patients 15\% - 35\% [28]. Correct clinical diagnosis in young women also is more difficult and reported higher negative appendectomy rate in this age group [14]. Furthermore most of our cases were in third Trimester66\% (N $=41$ ) with increasing gestational age reduces diagnostic accuracy and is associated with increased rates of appendiceal perforation and hence complications [28].

We have no maternal or fetal mortality, preterm labor or preterm delivery, morbidity also were as same as non-pregnant, meanwhile no used any hormonal, or tocolytic agent, but in a study in spite of tocolytic administration Preterm labor occurred in 10 patients (30\%), one of whom experienced preterm delivery [31]. So any effort must be done on time operation we operated the patients short time period between consultation within 12 hours. So, there was no appendical perforation or peritonitis. Hospital stay and operation time also were no longer than non-pregnant women. In conclusion appendicitis in pregnancy should be suspected when complains of new abdominal pain. No laboratory finding is diagnostic. Careful history and physical examination and close observation of $12 \pm 8$ hours are sufficient for surgery decision making. In spite of high negative appendectomy since it has no Surgical and obstetric complication, early appendectomy without aggressive investigation recommend.

\section{Footnote}

Authors' Contribution: All authors had equal role in design, work, statistical analysis and manuscript writing.

\section{References}

1. Pastore PA, Loomis DM, Sauret J. Appendicitis in pregnancy.JAm Board Fam Med. 2006;19(6):621-6. [PubMed: 17090795].

2. Eryilmaz R, Sahin M, Bas G, Alimoglu O, Kaya B. Acute appendicitis during pregnancy. Dig Surg. 2002;19(1):40-4. [PubMed: 11961354].

3. Mourad J, Elliott JP, Erickson L, Lisboa L. Appendicitis in pregnancy: new information that contradicts long-held clinical beliefs. Am J Obstet Gynecol. 2000;182(5):1027-9. [PubMed: 10819817].

4. Tamir IL, Bongard FS, Klein SR. Acute appendicitis in the pregnant patient. Am J Surg. 1990;160(6):571-6.

5. Ueberrueck T, Koch A, Meyer L, Hinkel M, Gastinger I. Ninetyfour appendectomies for suspected acute appendicitis during pregnancy. World J Surg. 2004;28(5):508-11. doi: 10.1007/s00268-004-7157-2. [PubMed: 15085399].

6. Nunnelee JD, Musselman R, Spaner SD. Appendectomy in pregnancy and postpartum: analysis of data from a large private hospital. Clin Excell Nurse Pract. 1999;3(5):298-301. [PubMed: 10763629].

7. Brown JJ, Wilson C, Coleman S, Joypaul BV. Appendicitis in pregnancy: an ongoing diagnostic dilemma. Colorectal Dis. 2009;11(2):116-22. doi: 10.1111/j.1463-1318.2008.01594.x. [PubMed:18513191].

8. Kapan S, Bozkurt MA, Turhan AN, Gonenc M, Alis H. Management of acute appendicitis in pregnancy. Ulus Travma Acil Cerrahi Derg. 2013;19(1):20-4. doi: 10.5505/tjtes.2013.81889. [PubMed: 23588974].

9. Sauerland S, Lefering R, Neugebauer EA. Laparoscopic versus open surgery for suspected appendicitis. Cochrane Database Syst Rev. 2004(4):CD001546. doi: 10.1002/14651858.CD001546.pub2. [PubMed: 15495014].

10. Kilpatrick CC, Monga M. Approach to the acute abdomen in pregnancy. Obstet Gynecol Clin North Am. 2007;34(3):389-402. doi: 10.1016/j.ogc.2007.06.002. [PubMed:17921006] x.

11. Stone K. Acute abdominal emergencies associated with pregnancy. Clin Obstet Gynecol. 2002;45(2):553-61. [PubMed: 12048412].

12. Yilmaz HG, Akgun Y, Bac B, Celik Y. Acute appendicitis in pregnancyrisk factors associated with principal outcomes: a case control study. Int J Surg. 2007;5(3):192-7. doi: 10.1016/j.ijsu.2006.05.005. [PubMed: 17509502]. 
13. McGory ML, Zingmond DS, Tillou A, Hiatt JR, Ko CY, Cryer HM. Negative appendectomy in pregnant women is associated with a substantial risk of fetal loss. J Am Coll Surg. 2007;205(4):534-40. doi: 10.1016/j.jamcollsurg.2007.05.025. [PubMed:17903726].

14. Al-Fozan H, Tulandi T. Safety and risks of laparoscopy in pregnancy. Curr Opin Obstet Gynecol. 2002;14(4):375-9. [PubMed: 12151826].

15. Hee $P$, Viktrup L. The diagnosis of appendicitis during pregnancy and maternal and fetal outcome after appendectomy. Int J Gynaecol Obstet. 1999;65(2):129-35. [PubMed: 10405056].

16. Al-Hashemy AM, Seleem MI. Appraisal of the modified Alvarado Score for acute appendicits in adults. Saudi Med J. 2004;25(9):1229-31. [PubMed: 15448772].

17. Lim HK, Bae SH, Seo GS. Diagnosis of acute appendicitis in pregnant women: value of sonography. AJR Am J Roentgenol. 1992;159(3):539-42. doi: 10.2214/ajr.159.3.1503019. [PubMed: 1503019].

18. Lazarus E, Mayo-Smith WW, Mainiero MB, Spencer PK. CT in the evaluation of nontraumatic abdominal pain in pregnant women. Radiology. 2007;244(3):784-90. doi: 10.1148/radiol.2443061634. [PubMed: 17709829].

19. Birchard KR, Brown MA, Hyslop WB, Firat Z, Semelka RC. MRI of acute abdominal and pelvic pain in pregnant patients. $A J R$ Am J Roentgenol. 2005;184(2):452-8. doi: 10.2214/ajr.184.2.01840452. [PubMed: 15671363].

20. Tracey M, Fletcher HS. Appendicitis in pregnancy. Am Surg. 2000;66(6):555-9. [PubMed: 10888131] discussion 559-60.

21. Butala P, Greenstein AJ, Sur MD, Mehta N, Sadot E, Divino CM. Surgical management of acute right lower-quadrant pain in pregnancy: a prospective cohort study. J Am Coll Surg. 2010;211(4):490-4. doi: 10.1016/j.jamcollsurg.2010.06.004. [PubMed: 20822740].

22. Singh A, Danrad R, Hahn PF, Blake MA, Mueller PR, Novelline RA. MR imaging of the acute abdomen and pelvis: acute appendicitis and beyond. Radiographics. 2007;27(5):1419-31. doi: 10.1148/rg.275065021.
[PubMed: 17848700].

23. Greenhalgh R, Punwani S, Taylor SA. Is MRI routinely indicated in pregnant patients with suspected appendicitis after equivocal ultrasound examination?. Abdom Imaging. 2008;33(1):21-5. doi: 10.1007/s00261-007-9300-7. [PubMed: 17874265].

24. Jackson H, Granger S, Price R, Rollins M, Earle D, Richardson W, et al. Diagnosis and laparoscopic treatment of surgical diseases during pregnancy: an evidence-based review.SurgEndosc. 2008;22(9):1917-27. doi: 10.1007/s00464-008-9989-6. [PubMed: 18553201].

25. Choi JJ, Mustafa R, Lynn ET, Divino CM. Appendectomy during pregnancy: follow-up of progeny. J Am Coll Surg. 2011;213(5):627-32. doi: 10.1016/j.jamcollsurg.2011.07.016. [PubMed: 21856183].

26. Machado NO, Grant CS. Laparoscopic appendicectomy in all trimesters of pregnancy. JSLS. 2009;13(3):384-90. [PubMed:19793481].

27. Walsh CA, Tang T, Walsh SR. Laparoscopic versus open appendicectomy in pregnancy: a systematic review. Int J Surg. 2008;6(4):339-44. doi: 10.1016/j.ijsu.2008.01.006. [PubMed: 18342590].

28. Maslovitz S, Gutman G, Lessing JB, Kupferminc MJ, Gamzu R. The significance of clinical signs and blood indices for the diagnosis of appendicitis during pregnancy. Gynecol Obstet Invest. 2003;56(4):188-91. [PubMed: 14576469].

29. Shimizu T, Ishizuka M, Kubota K. A lower neutrophil to lymphocyte ratio is closely associated with catarrhal appendicitis versus severe appendicitis. Surg Today. 2016;46(1):84-9. doi: 10.1007/s00595-0151125-3. [PubMed: 25686778].

30. Ito $\mathrm{K}$, Ito $\mathrm{H}$, Whang EE, Tavakkolizadeh A. Appendectomy in preg nancy: evaluation of the risks of a negative appendectomy. Am J Surg. 2012;203(2):145-50. doi: 10.1016/j.amjsurg.2011.02.010. [PubMed: 21784406].

31. Kumamoto K, Imaizumi H, Hokama N, Ishiguro T, Ishibashi K, Baba K, et al. Recent trend of acute appendicitis during pregnancy. Surg Today. 2015;45(12):1521-6. doi: 10.1007/s00595-015-1139-x. [PubMed: 25721173]. 